\title{
IMPROVEMENT OF SKIN SYMPTOMS AND MINERAL IMBALANCE BY DRINKING DEEP SEA WATER IN PATIENTS WITH ATOPIC ECZEMA/DERMATITIS SYNDROME (AEDS)
}

\author{
Hajime Kimata', Hideyuki Tai ${ }^{2}$, Koji Nakagawa ${ }^{2}$, Yoshindo Yokoyama ${ }^{2}$, Hiroshi Nakajima ${ }^{2}$, Yoshinari Ikegami ${ }^{2}$ \\ Unitika Central Hospital, Uji-City, Kyoto Prefecture, Japan: Department of Allergy ${ }^{1}$; Ako Kasei Co., Ltd., Ako-City, Hyogo \\ Prefecture, Japan ${ }^{2}$
}

Summary: Deep sea water intake improves skin symptoms and mineral imbalance and decreases serum IgE levels mad IgEinducing cytokines, IL-4, IL-13 and IL-18 in patients with atopic eczema/dermatitis syndrome (AEDS), while distilled water intake fails to do so.

Key words: Atopics eczema/dermatitis syndrome; Deep sea water; Hair analysis; IgE; Magnesium

\section{Introduction}

Magnesium $(\mathrm{Mg})$ is involved in the regulation of immune responses. It has been reported that in $\mathrm{Mg}$ deficient rats, serum levels of substance P, histamine, interleukin-1 (IL-1), IL-6 and tumor necrosis factor-alpha were elevated (5). Mg deficiency also caused atopic eczema/dermatitis syndrome (AEDS)-like symptoms in hairless rats (3).

We have previously reported that drinking of refined deep sea water that contains $\mathrm{Mg}$ as its main cation signigicantly reduces whole blood flow time and blood pressure in healthy volunteers (4). We have now studied the effect of drinking deep sea water on patients with AEDS.

\section{Materials and method}

Deep sea water, Amami no Mizu Hardness 1000 (Ako Kasei Co. Ltd.), obtained at $344 \mathrm{~m}$ depth and refined, contained $\mathrm{Mg}$ as well as other minerals. $500 \mathrm{ml}$ of it contained $\mathrm{Mg}$ (100.0 mg), Na (37.0 mg), Ca (35.5 mg), and K (34.5 $\mathrm{mg}$ ) and other trace minerals (Zn: $2.0 \mu \mathrm{g}$. $\mathrm{Cu}: 2.2 \mu \mathrm{g}$. I: 4.5 ug. P: $4.5 \mu \mathrm{g}$, Se: $0.2 \mu \mathrm{g}$ ). After obtaining the informed consent, 8 patients with AEDS (range: 21-52 years, mean age: 36 years), drank $500 \mathrm{ml} /$ day of deep sea water (Amami no Mizu Hardness 1000). As control group, 10 patients with AEDS (range: $20-53$ years, mean age: 36 years) drank 500 $\mathrm{ml} /$ day of distilled water, which did not contain minerals. At baseline and after 1 year, skin symptoms were assessed by skin scoring system as previously reported (1). Briefly, assessment was done on a scale of 0 to 2 in ascending order of severity with respect to inflammation. These signs were assessed on 15 areas of the body (face, scalp, neck, right arm, left arm, right hand, left hand, trunk, back, pelvis, buttocks, right leg, left leg, tight foot and left foot). The maximum possible score was 30 . Hair minerals were analyzed by inductively coupled plasma mass spectrometry. Simultaneously, serum levels of anti-mite IgE, anti-Japanese cedar pollen IgE, IL-4, IL-13 and IL-18 were measured by ELISA (2). Patients were asked to maintain their skin cares with washing by povidone iodine followed with applying azulene ointment. Since $\mathrm{Mg}, \mathrm{K}$ and $\mathrm{Ca}$ interact mutually, the results of them were shown as $\mathrm{Mg} / \mathrm{K}$ and $\mathrm{Ca} / \mathrm{Mg}$ rations, while the levels of $\mathrm{Al}, \mathrm{Mg}, \mathrm{Pb}$ were shown as absolute values (PPM).

\section{Results}

As shown in Table 1, after 1 year, skin symptoms by skin score were significantly improved in deep sea water group, while they were unchanged in control group.

Hair analysis revealed elevated levels of $\mathrm{Mg} / \mathrm{K}$ and $\mathrm{ca} / \mathrm{Mg}$ ratios, $\mathrm{Al}, \mathrm{Hg}$ and $\mathrm{Pb}$ levels at baseline in both groups of patients. However, in deep sea group they returned to normal levels, while they were unchanged in control group. In both groups, serum levels of $\mathrm{Mg} / \mathrm{K}$ and $\mathrm{Ca} / \mathrm{Mg}$ ratios were within normal range at baseline, and they were unchanged after 1 year (data not shown). Moreover, serum levels of anti-Dermatophagoides pteronyssinus and antiJapanese cedar pollen IgE, and IgE-inducing cytokines IL-4, IL-13 and IL-18 were decreased significantly in deep water sea group, while they were not decreased in control group. 
Tab. 1: Effect of drinking deep sea water in patients with AEDS.

\begin{tabular}{|l|c|c|c|c|c|c|}
\hline & \multicolumn{3}{|c|}{ Deep sea water $(\mathrm{n} 8)$} & \multicolumn{3}{c|}{ Distilled water (n 10) } \\
\hline & Baseline & 1 year & $\mathrm{P}$ & Baseline & \multicolumn{1}{c|}{1 year } & $\mathrm{P}$ \\
\hline Skin score & $15.0 \pm 0.5$ & $6.1+0.2$ & $<0.01$ & $14.6+0.6$ & $14.8 \pm 0.7$ & $\mathrm{NS}$ \\
\hline Hair & & & & & & \\
$\mathrm{Mg} / \mathrm{K}$ ratio & $11.5+1.6$ & $2.3 \pm 0.4$ & $<0.01$ & $11.1 \pm 1.9$ & $10.9+1.8$ & $\mathrm{NS}$ \\
$\mathrm{Ca} / \mathrm{Mg}$ ratio & $19.4 \pm 0.8$ & $13.7+0.7$ & $<0.01$ & $18.7 \pm 0.7$ & $19.3+0.6$ & $\mathrm{NS}$ \\
$\mathrm{Al}(\mathrm{PPM})$ & $10.7+1.1$ & $6.9+0.7$ & $<0.01$ & $10.2 \pm 1.2$ & $10.4 \pm 1.0$ & $\mathrm{NS}$ \\
$\mathrm{Hg}(\mathrm{PPM})$ & $2.8+0.2$ & $1.2 \pm 0.1$ & $<0.01$ & $2.6+0.2$ & $2.5+0.2$ & $\mathrm{NS}$ \\
Pb (PPM) & $3.5 \pm 0.2$ & $1.1+0.1$ & $<0.01$ & $3.4 \pm 0.2$ & $3.5 \pm 0.2$ & $\mathrm{NS}$ \\
\hline Serum & & & & & & \\
Anti-mite IgE* & $71.8 \pm 5.6$ & $42.8+5.3$ & $<0.01$ & $70.7 \pm 5.8$ & $72.9+6.5$ & $\mathrm{NS}$ \\
Anti-JCP IgE** & $76.3 \pm 4.2$ & $32.5+3.9$ & $<0.01$ & $73.5 \pm 5.1$ & $75.5+6.2$ & $\mathrm{NS}$ \\
IL-4 (pg/ml) & $19.3+0.1$ & $7.7 \pm 0.1$ & $<0.01$ & $18.2+0.1$ & $18.5+0.1$ & $\mathrm{NS}$ \\
IL-13 (pg/ml) & $9.3 \pm 0.1$ & $5.1 \pm 0.1$ & $<0.01$ & $10.5+0.1$ & $10.9 \pm 0.1$ & $\mathrm{NS}$ \\
IL-18 (pg/ml) & $8.2 \pm 0.1$ & $5.2 \pm 0.1$ & $<0.01$ & $8.5+0.1$ & $9.0+0.1$ & NS \\
\hline
\end{tabular}

Values are the mean + SEM.

*Anti-Dermatophagoides pteronyssinus specific IgE (UA/ml)

**Anti-Japanese cedar pollen specific IgE (UA/ml)

\section{Discussion}

Although number is small, these results suggest that deep sea water intake may improve skin symptoms and mineral imbalance and decrease IgE production and IgE-inducing cytokines, IL-4, IL-13 and IL-18. Large scale of study which has been currently in progress is needed.

\section{References}

1. Hiratsuka S, Yoshida A, Ichioka C, Kimata H. Enhancement of in vitro spontaneous IgE production by topical steroids in patients with atopic dermatitis. J Allergy Clin Immunol 1996;98:107-13.

2. Kimata H. Selective enhancement of production of IgE, IgG4, and Th2-cell cytokine during the rebound phenomenon in atopic dermatitis and prevention by suplatast tosilate. Ann Allergy Asthma Immunol 1999;82:293-5.
3. Neckermann G, Bavandi A, Meingassner JG. Atopic dermatitis-like symptoms in hypomagnesaimic hairless rats are prevented and inhibited by systemic or topical SDZ ASW 981. Br J Dermatol 2000;142:669-79.

4. Tai $\mathrm{H}$, Nakagawa $\mathrm{K}$, Watanabe $\mathrm{Y}$ et al. Effect of high mineral water prepared from deep sea water in human blood pressure and hemorheological parameters. Deep Ocean Water Res 2000;1:53.

5. Weglicki WB, Phillips TM. Pathobiology of magnesium deficiency: a cytokine/neurogenic inflammation hypothesis. Am J Physiol 1992;263:R734-R737.

Submitted February 2002.

Accepted April 2002.

Hajime Kimata, M.D., Ph.D.,

Unitika Central Hospital, Department of Allergy, 24-1, Umonji,

Uji, Uji-City, Kyoto Prefecture,

611-0021 Japan.

e-mail: unitikah@m12.alpha-net.ne.jp 